\title{
Seizing and realizing the opportunity: A salutogenic perspective on rehabilitation after burnout
}

\author{
Roald Pijpker ${ }^{\mathrm{a}, *}$, Lenneke Vaandrager ${ }^{\mathrm{a}}$, Esther J. Veen ${ }^{\mathrm{b}}$ and Maria A. Koelen ${ }^{\mathrm{a}}$ \\ ${ }^{a}$ Health and Society, Department of Social Sciences, Wageningen University \& Research, The Netherlands \\ ${ }^{\mathrm{b}}$ Rural Sociology, Department of Social Sciences, Wageningen University \& Research, The Netherlands
}

Received 14 July 2020

Accepted 20 November 2020

\begin{abstract}
.
BACKGROUND: Most research on burnout has focused on its antecedents, correlates, and consequences. However, little empirical attention has been paid to what constitutes successful rehabilitation after burnout, especially among young employees.

OBJECTIVE: The present study empirically examined resources supporting successful rehabilitation after burnout among young employees (between 18 and 35 years of age) from a salutogenic perspective.

METHODS: Interpretative phenomenological analysis was used as a methodological framework to explain the experiences of young employees underlying their rehabilitation after burnout.

RESULTS: The analysis showed that the rehabilitation process comprises four phases: 1) facing the crisis; 2) addressing the root causes; 3) seizing and achieving the opportunity; and 4) staying at work. Essential overarching resources facilitating successful recovery after burnout included receiving social support from family, friends, and colleagues, as well as having a feeling of control over the rehabilitation process. Participants learned to be aware of potential pitfalls that could trigger burnout symptoms, while having confidence in their ability to prevent burnout from reoccurring. These continuous learning processes were experienced as a prerequisite to remain at work.
\end{abstract}

CONCLUSIONS: Receiving social support and experiencing a feeling of control over the rehabilitation process appear to be key resources in facilitating a stable, meaningful return to work after burnout.

Keywords: Coping, exhaustion, recovery, resources, workforce

\section{Introduction}

Burnout is defined as "a work-related state of exhaustion that occurs among employees, which is characterized by extreme tiredness, reduced ability to

*Address for correspondence: Roald Pijpker, MSc, Health and Society, Department of Social Sciences, Wageningen University, Hollandseweg 1, Wageningen, $6706 \mathrm{KN}$, The Netherlands. Tel.: +31620187620; E-mail: roald.pijpker@wur.nl. regulate cognitive and emotional processes, and mental distancing. These four core dimensions of burnout are accompanied by a depressed mood as well as by non-specific psychological and psychosomatic distress symptoms" [1]. Burnout leads to adverse psychological consequences (e.g., hospitalization for mental disorders), physical effects (e.g., musculoskeletal pain), and occupational consequences (e.g., high sick leave and replacement costs) [2]. In the 
Netherlands, burnout is a significant cause of absenteeism, with associated sick-leave costs amounting to $€ 2.6$ billion annually [3]. Burnout complaints have risen substantially during the last decade, particularly among young employees between the ages of 18 and 35 years [4]. For this age group, burnout complaints have increased from $25 \%$ in 2014 to $33 \%$ in 2019 [4, 5], with the actual number of days on sick leave due to burnout rising from $7.8 \%$ in 2014 to $9.3 \%$ in 2019 [6]. Most studies on burnout have focused on predictors and outcomes [7-9], paying little attention to what constitutes successful rehabilitation (i.e., reducing burnout complaints, facilitating return to work) [10, 11]. Given the recent substantial increase in burnout complaints and duration of sick-leave among young employees $[4,5]$, it is essential to find strategies to support rehabilitation following burnout.

Although burnout is prevalent across the globe [2], each country has its own rehabilitation system [12]. In the Netherlands, the Occupational Disability Act of 2005 shifted the focus from assessing the disabilities of employees to evaluating their remaining capabilities, with an emphasis on prevention and early intervention [12]. The rationale behind this strategy is that initial assessment promotes rehabilitation, thereby allowing employees to return to work quickly, whether with their current employers or elsewhere. As a robust incentive to speed up the rehabilitation process, employers are obligated to pay for sick leave for up to two years. Finally, private enterprises (i.e., "rehabilitation bureaus") specialized in assisting rehabilitation can provide advice and coaching to employers concerning how to develop and implement a rehabilitation plan [12].

Recent literature reviews [10, 13-16] have consistently demonstrated that the effects of burnout interventions are not sustainable and that they are suboptimal in facilitating rehabilitation. Interventions seem to reduce burnout complaints to only a limited extent, with a tendency to facilitate partial rather than a full return to work [10, 13-17]. More specifically, according to a recent longitudinal study [18], the reduction of long-term burnout complaints and the promotion of RTW are two distinct and independent processes, neither of which is well understood. The relative ineffectiveness of rehabilitation interventions and the contradiction between alleviating burnout complaints and facilitating RTW suggest that additional research is needed in order to understand what constitutes successful rehabilitation.

Only a handful of studies have aimed to explain successful rehabilitation after burnout [19], with each study focusing on a specific burnout-rehabilitation program [20,21]. The results of these studies emphasize the need to addressing both personal (e.g., coping skills) and work-related factors (e.g., reducing workload), while taking into account the specific needs of individual employees. This knowledge nevertheless provides only a partial explanation of successful recovery from burnout, as the effects of rehabilitation programs are not sustainable in the long-term [10]. Moreover, a focus on predefined or standard rehabilitation programs does not allow for the examination of other factors that may facilitate successful rehabilitation. Areas that have yet to receive sufficient research attention include what happens after the end of a rehabilitation program and how employees remain at work. It would therefore be worthwhile to explore the general experiences underlying young employees' recovery from burnout, without explicitly focusing on any specific rehabilitation program. To this end, the present study is intended to investigate successful rehabilitation after burnout among young employees in the Netherlands.

\subsection{Salutogenic perspective on rehabilitation after burnout}

This study adopts a salutogenic perspective on rehabilitation. Unlike the pathogenic perspective, which focuses on factors that contribute to disease and illness, the salutogenic perspective explicitly focuses on understanding and explaining factors that support health and well-being [22]. The theory was developed by Aaron Antonovsky (1923-1994), who assumed that stressful events are an inherent part of life and that the development of health is dependent on the ability of individuals to adapt to what happens to them [23]. In this study, burnout is regarded as one such stressful event, focusing on how young employees recover their ability to rehabilitate successfully.

The ability to cope with stressful events in a healthpromoting way reflects the key concept of salutogenesis: the sense of coherence (SOC) [22]. The concept of SOC refers to the extent to which people experience life as comprehensible, manageable, and meaningful [22]. An ample body of research has provided support for the notion that employees with a strong SOC can cope effectively with stressful events in ways that promote health [24, 25]. For example, strong SOC scores have been shown to predict and explain high levels of workplace well-being and low levels of burnout complaints [26, 27]. The base of evidence supporting 
Table 1

Participant overview

\begin{tabular}{|c|c|c|c|c|c|c|}
\hline Name $^{\mathrm{a}}$ & Gender & Working status & Occupation before burnout & Occupation at interview & $\begin{array}{l}\text { Rehabilitation } \\
\text { duration - } \\
\text { in months }\end{array}$ & $\begin{array}{l}\text { Interview } \\
\text { time - } \\
\text { in minutes }\end{array}$ \\
\hline Deborah $^{b}$ & $\mathrm{~F}$ & $100 \%$ (5 days per week) & Scientist & $\begin{array}{l}\text { Change agent living } \\
\text { environments }^{\mathrm{d}}\end{array}$ & 12 & $120+50^{\mathrm{f}}$ \\
\hline Maya $^{b}$ & $\mathrm{~F}$ & $80 \%$ (4 days per week) & Marketing / consultant & Marketing / consultant ${ }^{\mathrm{c}}$ & 14 & $75+55^{\mathrm{f}}$ \\
\hline $\mathrm{Jack}^{\mathrm{b}}$ & M & $80-100 \%$ & Financial consultant & $\begin{array}{l}\text { Company owner (advisor } \\
\text { workplace health) }{ }^{\mathrm{d}}\end{array}$ & 5.5 & 125 \\
\hline Clara $^{\mathrm{b}}$ & $\mathrm{F}$ & $100 \%$ & Marketing at a university & Scientist $\mathrm{t}^{\mathrm{c}}$ & 18 & $97+45^{\mathrm{f}}$ \\
\hline Charles $^{\mathrm{b}}$ & M & $100 \%$ & $\begin{array}{l}\text { Project leader, railway } \\
\text { construction }\end{array}$ & $\begin{array}{l}\text { Project leader, railway } \\
\text { construction }^{\mathrm{c}}\end{array}$ & 6 & $96+43^{f}$ \\
\hline Anna $^{\mathrm{b}}$ & $\mathrm{F}$ & $80-100 \%$ & $\begin{array}{l}\text { Traineeship Ministry of } \\
\text { Health, Welfare and Sport, } \\
\text { advisor }\end{array}$ & $\begin{array}{l}\text { Company owner (lifestyle } \\
\text { coach) }{ }^{\mathrm{d}}\end{array}$ & 18 & 117 \\
\hline Ivanna & $\mathrm{F}$ & $80-100 \%$ & Scientist & Scientist $^{\mathrm{d}}$ & 18 & $109+52^{\mathrm{f}}$ \\
\hline Yasmine & $\mathrm{F}$ & $100 \%$ & ICT specialist & $\begin{array}{l}\text { Company owner (advisor } \\
\text { workplace health) }^{\mathrm{d}}\end{array}$ & 3 & 79 \\
\hline Yoshito & M & $20-40 \%$ & Scientist & Scientist, lecturer & $>15^{\mathrm{e}}$ & 154 \\
\hline
\end{tabular}

Note. The participants' ages at the time of the interviews were: 32, 27, 29, 26, 38, 29, 27, 31, 26 (to protect participants' identity, the ages are

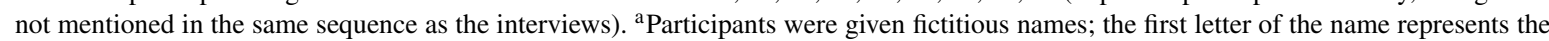
order of the interviews; ${ }^{\mathrm{b}}$ Contribution master student; ${ }^{\mathrm{c}}$ Change of job tasks / responsibilities; ${ }^{\mathrm{d}}$ Change of organization; ${ }^{\mathrm{e}}$ Still rehabilitating;

${ }^{\mathrm{f}}$ Participated in the participant check.

the positive effects of strong SOC on employee health and well-being is thus substantial [24]. The concept of SOC might therefore constitute an essential variable in the process of rehabilitation after burnout.

Prerequisites to the development of a strong SOC include an array of factors that have been identified as generalized resistance resources (GRRs) [28] and specific resistance resources (SRRs) [29]. A GRR is "any characteristic of the person, the group, or the environment that can facilitate effective coping" [23]. While GRRs are used to deal with a stressors in various contexts, SRRs differ from GRRs, in that they are specific to particular stressful events [29]. By successfully coping with stressful life events (e.g., by changing jobs), employees continuously learn to identify, mobilize, and use (or re-use) GRRs/SRRs, thereby strengthening their SOC [28, 29]. In this study, GRRs facilitate rehabilitation, but can also be applied in non-working contexts (e.g., receiving social support from family) can be used to cope with many different kinds of challenges. In contrast, SRRs support the ability to cope with specific challenges related to the consequences of being burned out (e.g., using professional help to prevent the recurrence of burnout). According to an increasing base of evidence, GRRs/SRRs to enhance SOC levels, and vice versa $[30,31]$. It is therefore interesting to identify GRRs and SRRs that support the successful rehabilitation of young employees after burnout.

\section{Method}

\subsection{Study design}

This study draws on the methodological framework of interpretative phenomenological analysis (IPA) [32], thereby adopting a qualitative approach [33] to explore how young employees perceive the resources that support successful rehabilitation after burnout. The salutogenic perspective was then applied as a framework for examining whether the resources identified are GRRs or SRRs.

\subsection{Participants}

Young employees (18-35 years of age when upon diagnosis of burnout) who have successfully rehabilitated after burnout were recruited through social media (e.g., Facebook), as well as through one general practitioner. Successful rehabilitation was defined as being employed in a situation that the participant considered satisfactory, with no desire to change jobs anytime soon. Ten prospective participants volunteered, and nine participants were selected based on the inclusion criteria (Table 1). The other young employee decided not participate in the study because of an adverse private situation. One of the nine participants that participated ultimately turned out not to be rehabilitated, but still allowed the identification of relevant resources. This 
participant was therefore included. The nine participants who were interviewed varied in terms of the rehabilitation period, occupation, and gender, but all were highly educated. Age at the time of burnout diagnosis ranged from 23 to 32 years, and age at the time of interview ranged between 26 and 38 years.

\subsection{Data collection}

Each participant was asked to prepare a timeline [34], which they subsequently used as support in the visual and chronological organization of experiences relating to the development of burnout and rehabilitation. Although the study focuses primarily on experiences concerning rehabilitation after burnout, the experiences that the participants described with regard to developing burnout and the consequences of burnout on their lives created a more comprehensive picture and facilitated an open dialogue about rehabilitation. Participants were free to determine how they would prepare the timeline, ranging from small drawings to large posters, which were then used to guide the interviews. In addition to allowing participants to share their personal stories chronologically, the timelines fostered a reflective dialogue [32]. The participants' explanations of their timelines allowed in-depth probing about particular events, feelings, and experiences underlying their recovery from burnout.

The interviews were conducted between October 2019 and February 2020. To help the participants feel at ease, the interviews were conducted in private locations. Five of the participants preferred to be interviewed in their homes, three chose to visit the university, and one requested to be interviewed in the workplace. For six of the interviews, a Master's student (female) assisted the principal investigator (male) in conducting the interviews, which allowed the participants to choose who would ask the questions. In all six cases, participants preferred that both researchers ask the questions. Audio recordings were made of the interviews, which lasted an average of 108 minutes. Additional data were collected through a participant check [32] with five respondents in May and June 2020. The participant check consisted of discussing the preliminary figure (i.e., the proposed model) of the results by asking the participants to reflect on the extent to which they could resonate with the model. The input from this reflective dialogue was then used to make final adjustments to the model and results.

\subsection{Data analysis}

The analytical approach consisted of two phases. Following the recommendations of Pietkiewicz and Smith [35], the analysis was conducted manually, in order to allow in-depth engagement with the data. The first phase entailed an case-by-case ideographic analysis. This was followed by the second phase, which consisted of cross-case analysis, based on IPA [32]. The first phase entailed four steps performed by the principal investigator: (a) before the iterative and inductive cycle started, the interview recordings were listened to multiple times while (b) reading and re-reading the transcripts. Emergent themes (c) at an explanatory level were added to the transcript, after which (d) the impact of burnout on the lives of the participants and how they had rehabilitated after burnout were described. Before these iterative steps, all authors pilot-tested the steps independently based on two interviews, which resulted in similar findings. In addition, the Master's student who had assisted with the interviews also assisted with the analysis of the first four interviews. During the second phase, overarching themes and rehabilitation phases were identified by searching for patterns across cases [32]. All researchers contributed to the analysis, as well as to the discussion of themes and abstractions.

The two inductive phases, were followed by deductive analysis, in which the findings were explored from the salutogenic perspective. The data were reorganized into components of the salutogenic model of health, focusing on resources and classifying them as either GRRs or SRRs. This process included several iterations between the transcripts (or audio recordings) and codes, with the goal of understanding the broader contexts of the participants, as well as their original statements and meanings [32, 35]. Accordingly, the main findings and relevant quotations were extracted. The participant check is an essential step when using IPA [32]. In this check, the first author facilitated a reflective dialogue, in which the participants were asked to reflect on the extent to which they could resonate with the findings, thereby enhancing the reliability of the results [32].

\subsection{Ethical considerations}

The methodology for this study was approved by the Social Sciences Ethics Committee (Wageningen University \& Research) on June 13, 2019. Prior to the interviews, the first author telephoned or visited the prospective participants to inform them about 
the aims of the study. The researchers were aware that the interviews involved a potential risk of retraumatization by asking the participants to revisit they had experienced. The participants were informed about this possibility and were told that they could contact the interviewer at any time to arrange a meeting with an occupational health physician, if needed. In addition, the researcher contacted the participants by telephone one week after the interview to ask how they were doing. Each participant provided signed informed consent before the interviews took place.

\section{Results}

In this section, the findings on the successful rehabilitation after burnout among employees are presented. Improving understanding concerning how GRRs and SRRs contribute to successful recovery from burnout requires first explaining how young employees experience the impact of burnout in their lives, with burnout defined in the salutogenic model as a stressful life event. The participants are listed in Table 1, using pseudonyms to protect their identities.

\subsection{Being burned-out as a stressful live event}

The overarching theme of having lost control over one's (working) life captures the significant impact of burnout on the lives of participants. All of the participants described the experience of being burned-out as terrible, characterized by a feeling of extreme exhaustion (both physically and mentally), an inability to think clearly, and an inability to control emotions. In addition, some participants reported depressive feelings, suicidal thoughts, and a range of psychosomatic distress symptoms, including headaches, panic attacks, and palpitations. All of these complaints had adverse effects on the health and well-being of the participants, as well as on their ability to work, thereby resulting in feelings of hopelessness with no perspective on the way out. As explained by Maya:

Being burned-out felt like a volcano eruption ...destroying my health, my well-being, and my life. I had no hope that I would ever recover, and I could not even think about work, let alone returning to work. I have never felt so weak, tired, and done with my life... I was utterly hopeless, and I had no perspective on a possible way out.

\subsection{GRRs and SRRs supporting rehabilitation after burnout}

The analysis revealed several interesting parallels among the rehabilitation processes of the participants, despite differences in situation and context. The rehabilitation process can be categorized into four phases: 1) facing the crisis; 2) addressing the root causes; 3 ) seizing and achieving the opportunity; and 4) staying at work (Fig. 1). Two GRRs (receiving social support and a feeling of control) were identified as essential drivers underlying the overall rehabilitation process. In Phases 1 and 2, the emphasis lies on coping with the consequences of burnout, whereas Phases 3 and 4 entail a learning process aimed at achieving and sustaining a stable and meaningful working life.

\subsubsection{Phase 1: Facing the crisis}

After being diagnosed with burnout, participants first needed to accept the situation (GRR) of not being able to do anything at all, let alone return to work. This was difficult for many respondents, primarily because none of them had expected that burnout would ever happen to them. Deborah explains how her perception of burnout changed from seeing it as something that happens only to weak people to accepting all the consequences of being burned-out and the need for change:

[before the burnout]... When people talked about burnout, I always thought, how can you be like that ... what kind of loser are you?

[being burned-out]... I felt terrible and completely hopeless... It made me realize that something had gone terribly wrong, and I was surprised that I had not been able to see this coming... I didn't know how, but knew I had to recover and learn to prevent this situation from happening again.

Related to accepting the situation is the feeling of "being or feeling like a patient," which can be both beneficial (SRR) and detrimental to the rehabilitation process. The experiences of Yoshito and Ivanna illustrate this discrepancy.

[Yoshito] ... when I was burning out, no one took me seriously, and they thought I was overreacting. After receiving the burnout diagnosis, it was liberating for me, as it provided confirmation that I am not wrong or crazy ... I suddenly received more support from friends and in-laws. 


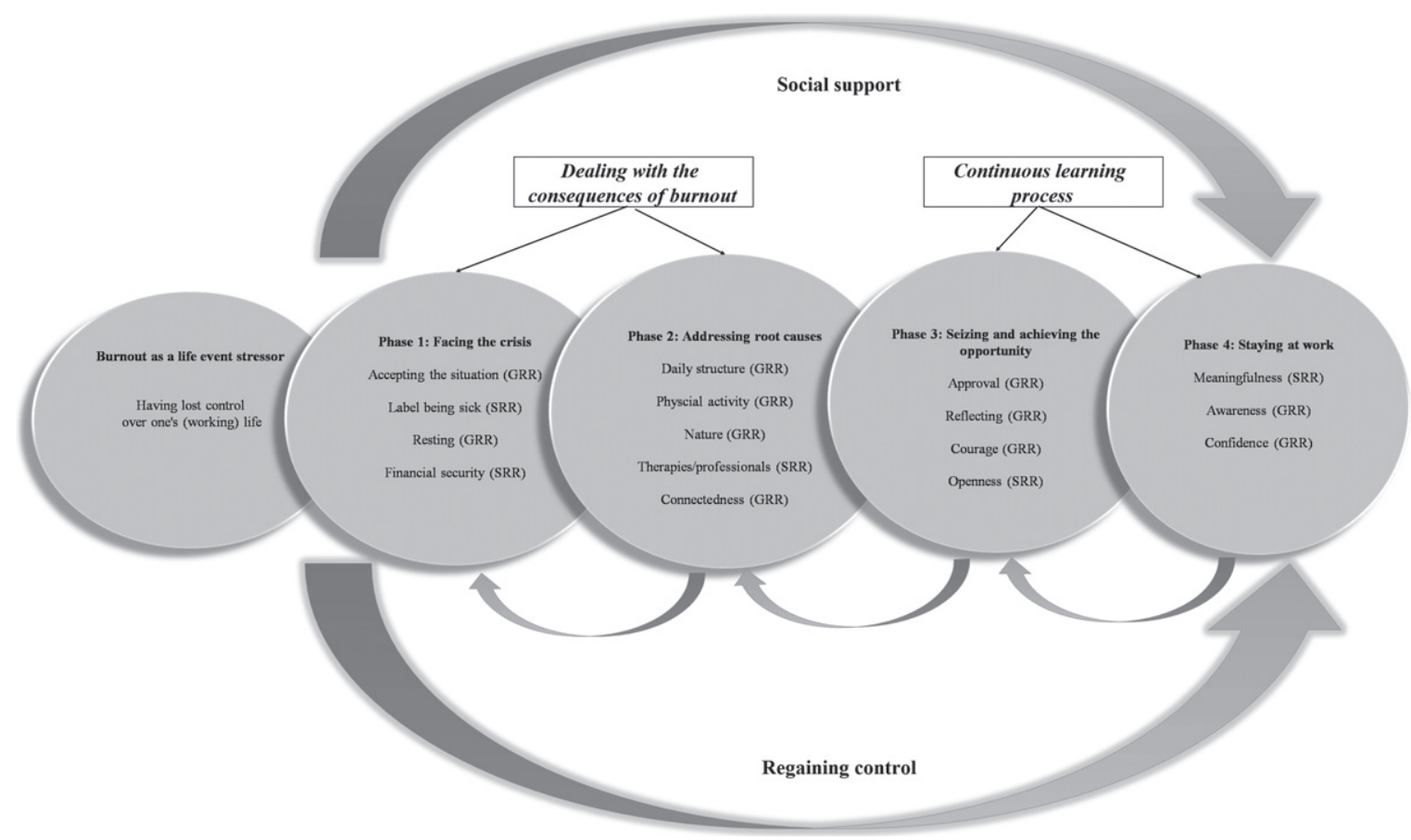

Fig. 1. Results of the analysis showing the four rehabilitation phases and which GRRs / SRRs facilitate successful rehabilitation from burnout among young employees.

[Ivanna] ... I never liked the label of burnout ... Not only because burnout was controlling my entire life, but also because it caused even more stress based on "being-sick or being a patient"... This somehow amplified the negative thoughts.

While coming to accept the situation, the participants required a large amount of rest (GRR), which was an inevitable consequence of being completely exhausted (both mentally and physically). It was thus not a choice. In practice, taking rest entailed sleeping for many hours during the day and doing little to nothing at all. This is explained by Clara, who experienced burnout only a few months after starting her dream job as a junior scientist:

I couldn't do anything more than sleep and cry in my bed ... I just kept asking, "Why is this happening to me?" ... I couldn't even watch Netflix series or movies, nor could I read books ... I knew I had to work on myself in order to return to work, but I couldn't do anything at all. That was hard, but it also felt good to allow my body to rest ...It was not a choice; my body forced me to do so ... especially after fainting at work and being brought home by colleagues.
Most respondents had not been concerned about their financial situations, as they received economic benefits through the Dutch public welfare system, which covered most of their formal salary during the first year (SRR: financial security). The participants were required to maintain contact with their employers or occupational health physicians. This was not the preference for most of them, however, as they felt that they needed time to recover and did not even think that much about their jobs (or returning to work). Instead, during this crisis phase, the participants experienced social support (GRR) from people close to them (e.g., family and friends) throughout the entire rehabilitation process. As explained by Anna:

I would never have recovered successfully from my burnout without the support of my boyfriend, friends, and family ... I was completely lost, and I didn't even dare to believe that anything would ever go to back to normal again ... Their support and advice were crucial to my recovery.

\subsubsection{Phase 2: Addressing root causes}

For all of the participants, the process of addressing the root causes of burnout started with creating a daily structure (GRR). All of the participants were entirely drained by doing little to nothing, and they 
believed that regaining a certain rhythm would be the first step towards successful recovery. In practice, this daily structure consisted of being physically active (GRR), as even easy cognitive tasks (e.g., reading books) were not possible. Activities included walking, baking cakes, or gardening — always followed by a period of rest. More specifically, most participants chose to be in nature (GRR), as it provided a setting in which they could rest while being physically active and away from intense environmental stimuli (as in a busy supermarket). Ivanna reflects:

I couldn't even go shopping or cross a busy street ... I really needed to escape to nature, as there was not so much noise or so many people ... Being in nature became part of the daily structure. I did a lot of walking, which made me feel at ease and less stressed ... However, I needed to take rest after walking in nature, as it was a demanding activity for my body.

While establishing daily structure, participants combined several therapies and professional help (SRR) to address the root causes underlying their burnout. In practice, participants consulted physiotherapists and haptonomists, aiming to learn how to recognize and understand what they were feeling in their bodies and minds. All of the participants stated that, throughout their lives, they had ignored—or had not been able to recognize-signals from their bodies. They noted that this was one of the causes of their burnout. By reconnecting with their bodies and minds, participants could better understand the signals that their bodies and minds were giving them, and this made them feel more relaxed than they had been before these therapies. Participants followed other courses as well (e.g., yoga, mindfulness, and meditation), in order to integrate being connected with their bodies and minds into their daily structures. At the same time, participants consulted psychologists to identify and address the causes underlying their burnout. In most cases, these causes were not related to the working context. In general, the participants wanted to prove their worth (both to themselves and to others). This need was rooted in low self-confidence and perfectionism resulting from past life experiences, which facilitated detrimental thinking and behavioral patterns, eventually resulting in burnout in the workplace. The "self-tailored" combination of therapies (both professional and otherwise) was experienced as essential to the recovery process, as explained by Deborah:
The cognitive-based therapy from the psychologist would never have been a success if I hadn't learned to listen to my body and understand what I'm actually feeling... At the psychologist's office, I was challenged to relive painful moments from my past, and I realized that I had never dealt with my feelings in a healthy manner ...This [realization] would not have been possible if I had not known how to identify and understand my feelings in my body and mind ...It taught me to listen to what I want and how I feel, rather than to what other people expect from me.

For most participants, daily structure, physical activity, therapies, and professional help created a feeling of control (GRR) over the recovery process. In other words, they felt that their ability to return to work would depend on the actions that they took to work on the root causes underlying their burnout. The participants therefore had a desire to reconnect (GRR) with the workplace. Most workplaces offered adjustments to participants who were returning to work, including a gradual increase in working hours and a temporary change in tasks. These participants perceived these adjustments were perceived as beneficial to the rehabilitation process, as their employers and colleagues provided both social support and understanding for their reduced ability to work. While some participants (e.g., Maya) were able to work 2-20 hours per week with no significant obligations, responsibilities, or deadlines, however, others (e.g., Anna) felt that they had no leeway for change in their tasks, thereby resulting in an immediate relapse to Phase 1:

My employer was very flexible about building up the hours gradually, but not about changing my tasks... I had the same responsibilities and hard deadlines, which forced me to do more than I actually could...I was not feeling happy about that, but did it [anyway], because it was expected of me ... At that time, I didn't listen to what I actually wanted, and this eventually led to a relapse to being completely burned-out.

\subsubsection{Phase 3: Seizing and achieving the opportunity}

Most participants started to return to work gradually, performing different tasks than they had before the burnout, with their tasks being customized to their specific capacities, needs, and limitations. At the same time, participants approved (GRR) of their 
"new selves," as Phase 2 had taught them what had gone wrong before the burnout, and they did not wish to end up in the same situation again. Accordingly, returning to work also provided a mirror that allowed participants to reflect (GRR) on their previous, current, and desired job situations, as well as on ways of working. Jack explains:

After returning to work, I did not understand why
everyone was working as they were ... I realized
that I had been the same way before: working
very intensely, with only short breaks (if any at
all) and then going home completely exhausted
.. I did my work very well, but I did not expe-
rience meaningfulness ... and I was tired of all
the procedures and hierarchal layers within the
organization... I realized that I wanted to start
my own company.

As a result of these insights, participants exhibited the courage (GRR) to implement real changes, with the goal of achieving a stable and meaningful return to work, aligned with the new self. Most participants changed their entire occupations and jobs. Even participants returning to the same employer made substantial adjustments to their ways of working, as illustrated by Clara:

It's not about how many hours you work, but how you work... My daily structure has changed completely. I get up, work at home, or go to a meeting, watch some series, have lunch with friends, do some sports and nothing more ...Although the project deadlines will never change, I've changed the way in which I meet them. Working fewer than 40 hours makes me work more productively than the 40 hours in my contract ... In academia, this way of working is quite unusual: my colleagues work from 8 to 5, plus overtime. I don't care what others think about the new me ... This feels so good to me, I am living my life rather than being dominated by the burnout or the expectations rooted in the academic system.

Returning to work was perceived as easier by participants who were able to be open (SSR) about their experiences with their employers. The explanations from Ivanna and Clara indicate why this is important to successful rehabilitation:

Ivanna [who was not able to share her experiences with her employer] Even though I don't care that much about what other people think about me ...It would be nice if my supervisors would understand what I' d been through in order to prevent burnout from recurring, as I genuinely love my job ...My supervisors, however, think that people with burnout do not belong in science, so I chose not to share it-not even with my new colleagues.

Clara [who was able to share her experience with her employer] I never found it difficult to share my experiences with anyone... Fortunately, my supervisors were very willing to listen to what I had experienced. They were also willing to adapt to the new me, even though nothing changed in my actual job or contract... The first thing on the agenda of the meeting with my supervisors is my health and well-being, which works well for my supervisors and me.

\subsubsection{Phase 4: Staying at work}

After making substantial changes regarding their work in Phase 3, almost all of the participants had made a stable return to work. Moreover, they perceived work as a source of meaningfulness (SRR), as reflected by Charles:

My working life is a source of joy ... I like my new work responsibilities, colleagues, and working culture. I have learned to let go of what other people think about or expect from me, and to choose for myself ...I'm not afraid to say "no" to my employer about doing specific tasks and, through discussion, we always find a satisfactory solution for both of us. I have no intention of changing my job anytime soon, although I do expect to grow further in the current organization.

Rehabilitation does not end after work has resumed. All of the participants were aware that there was a risk that burnout would recur if they were to step into the same pitfalls. Most of the participants were aware (GRR awareness) of the pitfalls that could trigger burnout symptoms, however, and they were confident (GRR) of their ability to prevent burnout from recurring. Maya provides a clear explanation:

Ilove the work that I' $m$ doing. Although the working culture is still the same ...I know that if I don't listen to my feelings or set limits for my colleagues, it will go wrong again ...At the same time, I don't exactly know what my limits are, but I can now recognize and understand signals from my body and mind ...I approach my new challenges at work with a feeling of confidence, and not with a sense of fear that it will go wrong. 


\section{Discussion}

\subsection{Summary of findings}

The present study is the first to use IPA and the theory of salutogenesis to investigate successful rehabilitation after burnout among young employees, without focusing on any specific rehabilitation program. Recovery entails four phases: 1 ) facing the crisis; 2) addressing the root causes; 3) seizing and achieving the opportunity; and 4) staying at work. Throughout these four phases, social support from friends, family, and colleagues/employer appear to be critical GRRs underlying successful rehabilitation for young employees, as does a feeling of control over the recovery process. Several resources were experienced as SRRs supporting their ability to cope with specific situations, as a consequence of their burnout. The SRRs identified by participants included receiving the burnout diagnosis and financial support (Phase 1), using a combination of therapies and professional help (Phase 2), being able to share experiences with colleagues (Phase 3), and experiencing work as a source of meaningfulness (Phase 4).

The results reveal interesting parallels with those of previous studies aimed at understanding successful rehabilitation after burnout among older employees. One particularly notable example is that social support and a feeling of control over the recovery process both serve as a driving force underlying rehabilitation [19-21]. The present study complements the existing literature by identifying specific GRRs/SRRs that facilitate coping with the consequences of burnout (Phases 1 and 2) and the continuous learning process needed in order to remain at work in a stable manner (Phases 3 and 4). The diversity of resources in each phase calls for an integrated approach, in which multiple professionals (e.g., occupational health physicians, psychologists, therapists) develop customized rehabilitation programs based on the needs and desires of young employees. To this end, rehabilitation bureaus are encouraged to initiate a reflective dialogue with young employees.

\subsection{Scientific implications}

The key GRR - feelings of control—relates to Rotter's [36] concept of locus of control, defined as a generalized expectation of correspondence between an individual's acts and the outcomes of those acts. While some people tend to see consequences resulting from their behavior (i.e., internal attributions), others tend to see outcomes as a result of external forces (i.e., external attributions) [37]. Previous studies have suggested that people who attribute outcomes to external forces can change such perceptions into a sense that certain outcomes (e.g., coping with an accidental injury) are under their control, as demonstrated in other rehabilitation programs [e.g., 37]. The findings of the present study support this notion, given that the young employees who were interviewed noted that they had received adequate social support from the very beginning, thus facilitated a sense that the recovery process was in their control. At the same time, however, the results also show that the social work environment should play a primary role in facilitating adequate social support. For example, young employees who were able to share recovery experiences with their employers were allowed more flexibility with their working schedules and tasks than was the case for those who were not able to share these experiences.

Being aware of possible pitfalls that could trigger burnout complaints, feeling confident in the ability to cope with challenges in order to prevent the recurrence of burnout complaints, and experiencing a meaningful working life are strongly related to the dimensions of SOC dimensions (comprehensibility-awareness, manageability-confidence, and meaningfulness). The rehabilitation process might thus reflect an experience that served to strengthen SOC for young employees who have recovered successfully. This is supported by a recent study, which suggests that experiencing and coping with stressful life events enhances GRRs and levels of SOC, while reinforcing optimal levels of mental health [38]. Longitudinal studies are needed in order to assess the extent to which the burnout-rehabilitation process can be regarded as an experience that strengthens SOC, in addition to identifying the GRRs/SRRs that contribute to successful rehabilitation (at least over time).

\subsection{Study limitations and strengths}

Although IPA provides a highly useful methodology for generating rich and nuanced insight into the experiences of research participants [32], some limitations should be discussed and taken into account when interpreting the results of this study (see Tuffour [39] for common limitations associated with the use of IPA). For instance, it is essential to bear in mind that IPA is fundamentally a subjective research approach $[32,39]$, which means that other researchers may 
find different results when replicating the present study. However, the participant checks indicated that the results had captured the experiences of the participants and allowed further clarification of the continuous learning process after returning to work (Phases 3 and 4), thereby enhancing the reliability of the findings. Also, the study is based only on "success cases," which did not allow comparisons with young employees who were still in the process of rehabilitating, or with those who saw themselves as having recovered but who had stopped working permanently. Future studies are encouraged to pursue such comparisons. Besides the limitations, the present study addressed a pivotal knowledge gap as not many studies focused on explaining successful rehabilitation after burnout [19-21], and none focused on young employees. Finally, most studies have employed interviews using predefined interview questions, whereas interviews in the present study were guided by timelines [34] made by the participants, which inevitably allowed probing on context-specific experiences and events underlying successful rehabilitation.

\section{Conclusions}

The rehabilitation process consists of four phases (i.e., facing the crisis; addressing the root causes; seizing and achieving the opportunity; and staying at work). Key GRRs underlying successful rehabilitation include social support from family, friends, and colleagues, along with an individual's feelings of control over the recovery process. Key SRRs include being labeled as sick and receiving financial support (Phase 1), using a combination of therapies and professional help (Phase 2), being able to share experiences with colleagues (Phase 3), and experiencing work as a source of meaningfulness (Phase 4). Phases 3 and 4 entail a continuous learning process, which enables young employees to maintain a stable and meaningful working life, thus constituting an experience that could potentially strengthen SOC.

\section{Acknowledgments}

This study was funded by the internal funds of two chair groups-Health and Society and Rural Sociology - at Wageningen University and Research in the Netherlands. We are grateful to all of our participants, who allowed an in-depth analysis of the phenomena of successful rehabilitation. Finally, we would like to thank Britt van Bladel (Master's student in Communication, Health, and Life Sciences) for her substantial contribution to the data collection.

\section{Conflict of interest}

The authors declare that they have no competing interest.

\section{References}

[1] Schaufeli W, de Witte, H, Desart, S. Scientific manual: burnout assessment tool. KU Leuven. 2019. http://burnout assessmenttool.be/wp-content/uploads/2019/10/Handleidi ng-BAT-engels-versie-1.4.pdf. Accessed 24 June 2020.

[2] Salvagioni DAJ, Melanda FN, Mesas AE, Gonozález AD, Gabani FL, Andrade SM. Physical, psychological and occupational consequences of job burnout: a systematic review of prospective studies. PLoS One. 2017;12(10): $1-29$.

[3] TNO Innovation for Life. Verzuimkosten door werkstress lopen op tot 2,8 miljard. 2019. https://www.tno.nl/nl/overtno/nieuws/2019/11/verzuimkosten-door-werkstresslopen-op-tot-2-8-miljard/. Accessed 24 June 2020.

[4] CBS Statline. Psychosociale arbeidsbelasting (PSA) werknemers; geslacht en leeftijd. 2020. https://opendata.cbs.n1/ statline/\#/CBS/nl/dataset/83049NED/table?ts=1592999067 847. Accessed 24 June 2020.

[5] RIVM. Health: how health will we be in the future? National Institute for Public Health and the Environment. 2018. https://www.vtv2018.nl/en/health. Accessed 24 June 2020.

[6] CBS Statline. Ziekteverzuim volgens werknemers; arbeidsomstandigheden. 2020. https://opendata.cbs.nl/statline/ \#/CBS/n1/dataset/83049NED/table?ts=1592999067847.

Accessed 24 June 2020.

[7] Parent-Lamarche A, Marchand A. Work stress, personality traits, and cortisol secretion: testing a model for job burnout. Work. 2018;60(3):485-97.

[8] Langballe EM, Innstrand ST, Hagtvet KA, Falkum E, Gjerløw AO. The relationship between burnout and musculoskeletal pain in seven Norwegian occupational groups. Work. 2009;32(2):179-88.

[9] Hallsten L, Voss M, Stark S, Josephson M. Job burnout and job wornout as risk factors for long-term sickness absence. Work. 2011;38(2):181-92.

[10] Pijpker R, Vaandrager L, Veen EJ, Koelen MA. Combined interventions to reduce burnout complaints and promote return to work: a systematic review of effectiveness and mediators of change. Int J Environ Res Public Health. 2019; 17(1):1-20.

[11] Kärkkäinen R, Saaranen T, Hiltunen S, Ryynänen OP, Räsänen K. Systematic review: factors associated with return to work in burnout. Occup Med. 2017;67(6):461-68.

[12] Goldenman G, Murphy G. Rehabilitation and return to work: Analysis report on EU and Member States policies, strategies and programmes. 2016. https://osha.europa.eu/ en/publications/rehabilitation-and-return-work-analysisreport-eu-and-member-states-policies-strategies/view. Accessed 24 June 2020. 
[13] de Weerd BJ, van Dijk MK, van der Linden JN, Roelen CA, Verbraak MJ. The effectiveness of a convergence dialogue meeting with the employer in promoting return to work as part of the cognitive-behavioural treatment of common mental disorders: a randomized controlled trial. Work. 2016;54(3):647-55.

[14] Perski O, Grossi G, Perski A, Niemi M. A systematic review and meta-analysis of tertiary interventions in clinical burnout. Scand J Psychol. 2017;58(6):551-61.

[15] Awa WL, Plaumann M, Walter U. Burnout prevention: a review of intervention programs. Patient Educ Couns. 2010; 78(2):184-90.

[16] Maricuţoiu LP, Sava FA, Butta O. The effectiveness of controlled interventions on employees' burnout: a metaanalysis. J Occup Organ Psychol. 2016;89(1):1-27.

[17] Blonk RWB, Brenninkmeijer V, Lagerveld SE, Houtman ILD. Return to work: a comparison of two cognitive behavioural interventions in cases of work-related psychological complaints among the self-employed. Work \& Stress. 2006;20(2):129-44.

[18] Vente W, Kamphuis JA, Blonk RWB, Emmelkamp PMG. Recovery of work-related stress: complaint reduction and work-resumption are relatively independent processes. J Occup Rehabil. 2015;25(3):658-68.

[19] Mårtensson L, Hensing G. Experiences of factors contributing to women's ability to make informed decisions about the process of rehabilitation and return to work: a focus group study. Work. 2012;43(2):237-48.

[20] Salminen S, Mäkikangas A, Hätinen M, Kinnunen U, Pekkonen M. My wellbeing in my own hands: experiences of beneficial Recovery during burnout rehabilitation. J Occup Rehabil. 2015;25(4):733-41.

[21] Fjellman-Wiklund A, Stenlund T, Steinholtz K, Christina A. Take charge: patients' experiences during participation in a rehabilitation programme for burnout. J Rehabil Med. 2010;42(5):475-81.

[22] Antonovsky A. Unraveling the mystery of health: how people manage stress and stay well. San Francisco: Jossey-Bass; 1987.

[23] Antonovsky A. Health, stress, and coping. San Francisco: Jossey-Bass; 1979.

[24] Mayer CH, Krause C. Promoting mental health and salutogenesis in transcultural organizational and work contexts. Int Rev Psychiatry. 2011;23(6):495-500.

[25] Eriksson M, Lindström B. Antonovsky's sense of coherence scale and its relation with quality of life: a systematic review. J Epidemiol. 2007;61(11):938-44.

[26] Fourie L, Rothmann S, van de Vijver FJ. A model of work wellness for non-professional counsellors in South Africa. Stress Health. 2008;24(1):35-7.
[27] Rothmann S, Steyn L, Mostert K. Job stress, sense of coherence and work wellness in an electricity supply organisation. South African Journal of Business Management. 2005;36(1):55-3.

[28] Idan O, Eriksson M, Al-Yagon M. The salutogenic model: the role of generalized resistance resources. In: Mittelmark MB, Sagy S, Eriksson M, Bauer GF, Pelikan JM, Lindström $\mathrm{B}$, Espnes G, editors. The handbook of salutogenesi. Cham: Springer Publishing; 2017. pp. 57-69.

[29] Mittelmark MB, Bull T, Daniel M, Urke H. Specific resistance resources in the salutogenic model of health. In: Mittelmark MB, Sagy S, Eriksson M, Bauer GF, Pelikan JM, Lindström B, Espnes G, editors. The handbook of salutogenesi. Cham: Springer Publishing; 2017. pp. 71-76.

[30] Pijpker R, Vaandrager L, Bakker EJ, Koelen M. Unravelling salutogenic mechanisms in the workplace: the role of learning. Gac Sanit. 2018;32(3):275-82.

[31] Vogt K, Hakanen, JJ, Jenny GJ, Bauer GF. Sense of coherence and the motivational process of the job-demandsresources model. J Occup Health Psychol. 2016;21(2): 194-207.

[32] Smith JA, Osborn M. Interpretative phenomenological analysis. In: Smith CA, editor. Qualitative psychology: a practical guide to research methods. California: Sage Publications; 2003. pp. 51-80.

[33] Tong A, Sainsbury P, Craig J. Consolidated criteria for reporting qualitative research (COREQ): a 32-item checklist for interviews and focus groups. Int J Qual Health Care. 2007;19(6):349-57.

[34] Sheridan J, Chamberlain K, Dupuis A, Timelining: visualizing experience. Qualitative Research. 2011:11(5):552-69.

[35] Pietkiewicz I. Smith JA. A practical guide to using interpretative phenomenological analysis in qualitative research psychology. Psychological Journal. 2014;20(1):7-14.

[36] Rotter JB. Generalized expectancies for internal versus external control of reinforcement. Psychological Monographs: General and Applied. 1966;80(1):1-28.

[37] Brewin CR. Adaptive aspects of self-blame in coping with accidental injury. In: Aataki C, Brewin CR, editors. Attributions and psychological change. London: Academic Press; 1982. pp. 119-134.

[38] Srensen T, Klungsyr L, Kleiner R, Klepp OM. Social support and sense of coherence: independent, shared and interaction relationships with life stress and mental health. Int J Ment Health Promot. 2011;13(1):27-44.

[39] Tuffour I. A critical overview of interpretative phenomenological analysis: a contemporary qualitative research approach. Int J Ment Health Promot. 2017;2(4):1-5. 